\title{
Efisiensi Harga dan Pendapatan Usaha Tani Stroberi
}

\author{
${ }^{1}$ Cyprianus P.H Saragi, dan ${ }^{2}$ Debby Chintia P. Barus \\ 1,2Program Studi Agribisnis, Fakultas Pertanian, Unika Santo Thomas \\ Email : cyprianus.phs07@gmail.com
}

\begin{abstract}
Abstrak
Penelitian ini bertujuan untuk 1) mengetahui pengaruh penggunaan faktor-faktor produksi terhadap produksi stroberi. 2) mengetahui efisiensi penggunaan faktor-faktor produksi. 3) mengetahui besarnya pendapatan bersih per hektar per musim tanam usahatani stroberi. Penelitian ini dilaksanakan di Dusun Tongkoh, Desa Dolat Rayat, Kecamatan Dolat Rayat, Kabupaten Karo. Penentuan sampel dilakukan dengan metode sensus sehingga besar sampel sebanyak $30 \mathrm{KK}$. Analisis data yang digunakan adalah analisis fungsi produksi Cobb Douglas, efisiensi harga, dan pendapatan. Hasil penelitian menunjukkan bahwa (1) secara serempak penggunaan faktor produksi pupuk kandang, pupuk daun, pupuk ammophos, insektisida, dan tenaga kerja berpengaruh nyata/signifikan terhadap produksi usahatani stroberi. Secara parsial penggunaan faktor produksi pupuk daun, pupuk ammophos, insektisida, dan tenaga kerja berpengaruh nyata terjadap produksi usahatani stroberi, sedangkan pupuk kandang tidak berpengaruh nyata/signifikan terhadap produksi usahatani stoberi, (2) penggunaan faktor produksi pupuk kandang, pupuk daun, pupuk ammophos, insektisida, dan tenaga kerja belum efisien, penggunaan faktor produksi tersebut masih dapat ditingkatkan untuk meningkatkan produksi usahatani stroberi, (3) pendapatan bersih petani stroberi sebesar sebesar Rp. $286.664 .036,00 / \mathrm{ha} / \mathrm{mt}$.
\end{abstract}

Kata kunci : Estimasi fungsi produksi stroberi, efisiensi alokatif, dan pendapatan bersih.

\section{Abstract}

This study aims at 1) Know the effect of the use of production factors on strawberry production. 2) Know the efficiency of using production factors. 3) Know the magnitude of net income per hectare per season of strawberry farming. This research was conducted in Tongkoh Hamlet, Dollat Rayat Village, Dollat Rayat District, Karo Regency. The sample determination was done by the census method so that the sample was as many as $30 \mathrm{KK}$. The data analysis used is analysis of the production function of Cobb Douglas, price efficiency, and income. The results showed that (1) Simultaneously the use of manure production factors, leaf fertilizers, ammophos fertilizers, insecticides, and labor have a significant / significant effect on the production of strawberry farming. Partially the use of leaf fertilizer production factors, ammophos fertilizers, insecticides, and labor have a significant effect of strawberry farming, while manure has no significant / significant effect on the production of stupidity, (2) The usege of production factors like manure fertilizer, leaf fertilizers, ammophos fertilizers, Insecticides, and the workforce is not yet efficient, the use of the production factor can still be increased to increase the production of strawberry farming, (3) Net income of strawberries farmers amounting to Rp.286,664,036.00 / ha / $\mathrm{mt}$.

Keyword: Estimated strawberry production function, alocative efficiency, and net income.

\section{PENDAHULUAN}

Komoditas hortikultura yang sangat potensial untuk memasuki pasar internasional dan pasar lokal adalah buah-buahan. Selain merupakan penyedia vitamin dan mineral bagi tubuh, buahbuahan juga mempunyai peluang pasar yang baik (Rahardi et al.,2003).

Stroberi (Fragaria sp) merupakan salah satu komoditas buah-buahan subtropis yang sangat potensial untuk dikembangkan di Indonesia. Tanaman stroberi termasuk tanaman yang memiliki nilai ekonomis tinggi, daya tariknya terletak pada warna buah yang merah mencolok dan rasanya manis segar (Soemadi, 1997). Stroberi bukan merupakan tanaman asli Indonesia, namun pengembangan komoditas ini yang berpola agribisnis dan agroindustri dapat dikategorikan sebagai salah satu sumber pendapatan baru dalam sektor pertanian (Rukmana, 1998).

Produksi stroberi cenderung meningkat dari tahun 2014-2017 namun terjadi penurunan produksi pada tahun 2018 menjadi 190 ton. Padahal di tahun 2018 terjadi peningkatan luas panen stroberi menjadi $34 \mathrm{Ha}$ namun tidak diimbangi dengan peningkatan produksi. Hal ini terjadi karena kurang terampilnya petani dalam mengombinasikan faktor-faktor produksi yang dimilikinya secara tepat dan efisien. Jika petani mampu mengalokasikan faktor-faktor produksinya secara efisien maka tujuan petani untuk memperoleh keuntungan yang maksimum dapat tercapai.

Berdasarkan latar belakang yang telah
diuraikan dapat dirumuskan beberapa 
permasalahan penelitian yaitu: 1) Bagaimana pengaruh penggunaan faktor-faktor produksi terhadap produksi stroberi? 2) Bagaimana tingkat efisiensi alokatif (harga) penggunaan faktor-faktor produksi stroberi? 3) Berapa besar pendapatan bersih per hektar per musim tanam usahatani stroberi?

Berdasarkan permasalahan di atas dapat dirumuskan tujuan penelitian yaitu: 1) Untuk mengetahui pengaruh penggunaan faktor-faktor produksi terhadap produksi stroberi. 2) Untuk mengetahui efisiensi penggunaan faktor-faktor produksi. 3) Untuk mengetahui besarnya pendapatan bersih per hektar per musim tanam usahatani stroberi.

Menurut Joesron dan Fathorrozi (2003) produksi merupakan hasil akhir dari proses atau aktivitas ekonomi dengan memanfaatkan beberapa masukan atau input. Dengan pengertian ini dapat dipahami bahwa kegiatan produksi adalah mengkombinasi berbagai input atau masukan untuk menghasilkan output. Jadi fungsi produksi adalah suatu persamaan yang menunjukkan jumlah maksimum output yang dihasilkan dengan kombinasi input tertentu.

Fungsi produksi Cobb-Douglas adalah suatu fungsi atau persamaan yang melibatkan dua atau lebih variabel; yaitu variabel dependen (Y) dan variabel independen (X). Secara matematik, fungsi produksi Cobb-Douglas dapat dituliskan sebagai berikut :

$\mathbf{Y}=\mathbf{b}_{0} \mathbf{X}_{1}{ }^{\mathrm{b} 1} \mathbf{X}_{2}{ }^{\mathrm{b} 2} \mathbf{X}_{3}{ }^{\mathrm{b} 3} \mathbf{X}_{4}{ }^{\mathrm{b} 4} \mathbf{X}_{5}{ }^{\mathrm{b} 5} \ldots . . \mathbf{X}_{\mathrm{i}}{ }^{\mathrm{bi}} \mathrm{e}^{\mu}$

Dimana:

$\mathrm{Y} \quad=$ Variabel yang dijelaskan

$\mathrm{X}=$ Variabel yang menjelaskan

$\mathrm{b}_{0} \quad=$ Konstanta

$\mathrm{b}=$ Besaran yang akan diduga

$\mathrm{e} \quad=$ Logaritma natural $(\mathrm{e}=2,178)$

$\mu \quad=$ Unsur sisa

Untuk memudahkan pendugaan terhadap persamaan tersebut maka persamaan itu diubah menjadi bentuk linear berganda dengan cara melogaritmakan persamaan tersebut. Logaritma dari persamaan diatas adalah:

$\log Y=\log b 0+b 1 \log X 1+b 2 \log X 2+$ b3 Log X3 + b4 Log X4 + b5 Log X5 + .....+ bi $\log \mathbf{X i}+\boldsymbol{\mu}$

Soekartawi (2003) berpendapat bahwa pendapatan usahatani adalah selisih antara penerimaan dan semua biaya yang dikeluarkan.

$\boldsymbol{\pi}=\mathbf{T R}-\mathbf{T C}$

Dimana:

$\pi=$ Pendapatan

$\mathrm{TR}=$ Total Revenue (Penerimaan Total)

$\mathrm{TC}=$ Total Cost $($ Biaya Total $)$

Penerimaan total (TR) adalah perkalian antara produksi yang diperoleh (Y) dengan harga jual (Py). Biaya total (total cost) adalah penjumlahan dari biaya tetap (fixed cost) dan biaya variabel (variable cost), maka $\mathrm{TC}=\mathrm{FC}+\mathrm{VC}$.

Menurut Kay dalam Saragi (1992) efesiensi harga berhubungan dengan keberhasilan pengusaha dalam mencapai keuntungan maksimum, hal ini dapat dicapai apabila nilai produk marginal (NPMx) sama dengan harga input (Px).

$\mathrm{NPM}_{\mathrm{xi}}=\mathrm{P}_{\mathrm{xi}}$ $\frac{\text { bi } \overline{\mathrm{Y}} \cdot \overline{\mathrm{Py}}}{\overline{\mathrm{X}} \mathrm{l}}=\mathrm{P}_{\mathrm{xi}}$ atau $\frac{\text { bi } \cdot \overline{\mathrm{Y}} \cdot \overline{\mathrm{Py}}}{\overline{\mathrm{X}} \cdot \overline{\mathrm{Pxl}}}=1$

dimana, $\mathrm{k}_{\mathrm{i}}=\frac{\overline{\mathrm{Y}} \cdot \overline{\mathrm{Py}}}{\overline{\mathrm{X}} \cdot \mathrm{Pxi}} \cdot$ bi sehingga, $\mathrm{ki}=1$

Dimana:

NPM = Nilai produksi marginal

$\bar{Y} \quad=$ Produksi rata-rata

$\overline{P Y}=$ Harga produksi rata-rata

$\overline{X l} \quad=$ Input rata-rata

$\overline{P x l} \quad=$ Harga input rata-rata

$\mathrm{Ki}=$ Tingkat efisiensi faktor produksi

Maka,

a. Jika nilai $\mathrm{K}_{\mathrm{i}}=1$ artinya penggunaan faktor produksi $\left(\mathrm{X}_{\mathrm{i}}\right)$ efisien.

b. Jika nilai $\mathrm{K}_{\mathrm{i}}<1$ artinya penggunaan faktor produksi $\left(\mathrm{X}_{\mathrm{i}}\right)$ tidak efisien sehingga perlu dilakukan pengurangan faktor produksi $\mathrm{X}$ agar dapat tercapai efisiensi.

c. Jika nilai $\mathrm{K}_{\mathrm{i}}>1$ artinya penggunaan faktor produksi $\left(\mathrm{X}_{\mathrm{i}}\right)$ belum efisien sehingga penambahan input masih dapat meningkatkan produksi.

\section{METODE PENELITIAN}

Penelitian ini dilakukan di Dusun Tongkoh, Desa Dolat Rayat, Kecamatan Dolat Rayat, Kabupaten Karo yang ditentukan secara purposive), dengan alasan desa ini merupakan salah satu sentra produksi stroberi di Kabupaten Karo.

Besar populasi dan sampel dalam penelitian ini adalah sebanyak $30 \mathrm{KK}$ yang ditentukan secara sensus.

Data yang dikumpulkan dalam penelitian ini terdiri dari data primer dan sekunder. Data primer diperoleh dengan melakukan wawancara dan pengamatan langsung ke petani dengan menggunakan kuesioner yang telah disiapkan sebelumnya. Data sekunder diperoleh melalui instansi yang terkait seperti Badan Pusat Statistik (BPS) dan Dinas Pertanian Kabupaten Karo, juga digunakan buku bacaan yang relevan dengan penelitian ini sebagai sumber literatur dan situssitus internet.

1. Untuk tujuan (1), dianalisis dengan menggunakan model fungsi produksi CobbDouglas dengan rumus sebagai berikut:

$\mathbf{Y}=\mathbf{b}_{0} \mathbf{X}_{1}{ }^{\mathrm{b} 1} \mathbf{X}_{2}{ }^{\mathrm{b} 2} \mathbf{X}_{3}{ }^{\mathrm{b} 3} \mathbf{X}_{4}{ }^{\mathrm{b} 4} \mathbf{X}_{5}{ }^{\mathrm{b5}} \mathrm{e}^{\mu}$

Dimana :

$\mathrm{Y} \quad=$ Produksi (ton)

$\mathrm{X}_{1} \quad=$ Pupuk kandang $(\mathrm{kg})$ 
$\mathrm{X}_{2} \quad=$ Pupuk daun (1)

$\mathrm{X}_{3} \quad=$ Pupuk ammophos $(\mathrm{kg})$

$\mathrm{X}_{4} \quad=$ Insektisida (l)

$\mathrm{X}_{5} \quad=$ Tenaga kerja (HKP)

$\mathrm{b}_{0} \quad=$ Intercept atau konstanta

$\mathrm{b}_{1} \ldots \mathrm{b}_{\mathrm{i}}=$ Besaran yang akan diduga

$\mathrm{e} \quad=$ Logaritma natural $(\mathrm{e}=2,718)$

$\mu \quad=$ Unsur sisa

Selanjutnya dilakukan Uji Statistik meliputi uji $\mathrm{R}^{2}$, uji $\mathrm{F}$, dan uji t. Uji asumsi klasik meliputi uji multikolinearitas, uji heterokedastisitas, dan uji normalitas.

2. Untuk tujuan (2), dianalisis berdasarkan konsep efisiensi harga. Secara matematis dapat dituliskan sebagai berikut :

$\mathrm{NPMx}_{\mathrm{i}} / \mathbf{P}_{\mathrm{xi}}=1 ; \operatorname{karena} \mathrm{NPMx}_{\mathrm{i}} / \mathbf{P}_{\mathrm{xi}}=\mathbf{k} ;$ maka $\mathbf{k}=$ 1

Hipotesis yang akan di uji adalah :

$\mathrm{H}_{0}$ : ki $=1$, berarti bahwa penggunaan input sudah efisien.

$\mathrm{H}_{1}$ : ki $\neq 1$, berarti bahwa penggunaan input belum efisien.

Apabila $\mathrm{t}$ hitung $>\mathrm{t}$ tabel maka $\mathrm{H}_{0}$ ditolak, $\mathrm{H}_{1}$ diterima artinya bahwa penggunaan faktor produksi ke-i belum efisien (Kay dalam Saragi, 1992).

3. Untuk tujuan (3), dianalisis dengan menggunakan rumus pendapatan. Pendapatan usahatani dapat dihitung dengan rumus : $\boldsymbol{\pi}=\mathbf{T R}-$ TC

\section{HASIL PENELITIAN DAN PEMBAHASAN}

A. Pengaruh Faktor-Faktor Produksi Terhadap Produksi Stroberi

Berdasarkan hasil analisis fungsi produksi Cobb-Douglas diperoleh persamaan regresi sebagai berikut:

$\log Y=\log (-1,279)+0,071 \log X 1+0,281 \log$ $\mathrm{X} 2+0,262 \log \mathrm{X} 3+0,304 \log \mathrm{X} 4+$ $0,293 \log X 5$

\section{Koefisien Determinasi}

Dari hasil perhitungan nilai koefisien determinasi $\left(\mathrm{R}^{2}\right)$ sebesar 0,951 menunjukkan bahwa 95,1\% variasi variabel dependen (produksi) usahatani stroberi dapat dijelaskan oleh variasi variabel independen yang terdapat dalam model, sedangkan sisanya sebesar $4,9 \%$ variasi variabel dependen dijelaskan oleh variasi variabel independen lain yang terdapat diluar model.

2. Uji F

Hasil perhitungan memperlihatkan nilai $\mathrm{F}$ hitung yang lebih besar dari pada nilai $F$ tabel pada $\alpha 0,05\left(\mathrm{~F}_{\text {hit }}=93,753>\mathrm{F}_{\text {tabel }}=2,60\right)$. Hal ini menunjukkan bahwa secara serempak variabel independen yaitu jumlah pupuk kandang, jumlah pupuk daun jumlah pupuk ammophos, jumlah insektisida, dan jumlah tenaga kerja berpengaruh secara signifikan terhadap variabel dependen yaitu produksi stroberi.

3. Uji Parsial a. Pupuk Kandang

Diketahui dari hasil analisis pada variabel pupuk kandang nilai $\mathrm{t}_{\text {hitung }}(0,524)<\mathrm{t}_{\text {tabel }}(1,708)$ pada tingkat kepercayaan $95 \%$, sehingga $\mathrm{H}_{0}$ diterima dan tolak $\mathrm{H}_{1}$. Secara parsial variabel pupuk kandang tidak berpengaruh nyata terhadap produksi usahatani stroberi.

b. Pupuk Daun

Diketahui dari hasil analisis pada variabel pupuk daun nilai $t_{\text {hitung }}(1,843)>\mathrm{t}_{\text {tabel }}(1,708)$ pada tingkat kepercayaan $95 \%$, sehingga $\mathrm{H}_{0}$ ditolak dan terima $\mathrm{H}_{1}$. Secara parsial variabel pupuk daun berpengaruh nyata terhadap produksi usahatani stroberi.

c. Pupuk Ammophos

Diketahui dari hasil analisis pada variabel pupuk ammophos nilai $t_{\text {hitung }}(2,273)>t_{\text {tabel }}(1,708)$ pada tingkat kepercayaan $95 \%$, sehingga $\mathrm{H}_{0}$ ditolak dan terima $\mathrm{H}_{1}$. Secara parsial variabel pupuk ammophos berpengaruh nyata terhadap produksi usahatani stroberi.

d. Insektisida

Diketahui dari hasil analisis pada variabel insektisida nilai $t_{\text {hitung }}(2,555)>t_{\text {tabel }}(1,708)$ pada tingkat kepercayaan $95 \%$, sehingga $\mathrm{H}_{0}$ ditolak dan terima $\mathrm{H}_{1}$. Secara parsial variabel insektisida berpengaruh nyata terhadap produksi usahatani stroberi.

e. Tenaga Kerja

Diketahui dari hasil analisis pada variabel Nilai $t_{\text {hitung }}(2,156)>t_{\text {tabel }}(1,708)$ pada tingkat kepercayaan $95 \%$, sehingga $\mathrm{H}_{0}$ ditolak dan terima $\mathrm{H}_{1}$. Secara parsial variabel tenaga kerja berpengaruh nyata terhadap produksi usahatani stroberi.

\section{B. Efisiensi Penggunaan Faktor Produksi \\ Usahatani Stroberi di Daerah Penelitian}

Dalam mengelola usahatani petani selalu berpikir bagaimana mengalokasikan faktor-faktor produksi yang dimiliki seefisien mungkin untuk memperoleh keuntungan yang maksimal. Berikut ini adalah faktor produksi yang digunakan pada usahatani stroberi.

\section{Tabel 2. Rata-Rata Penggunaan Faktor} Produksi Pada Usahatani Stroberi

\begin{tabular}{|l|l|c|}
\hline No & Sarana Produksi & Per Hektar \\
\hline 1 & Bibit (batang) & $62.500,00$ \\
2 & Pupuk & \\
& -Pupuk Kandang (kg) & $11.556,60$ \\
& -Pupuk Daun (l) & 21,14 \\
& -Pupuk NPK (kg) & $1.426,42$ \\
& -Pupuk KCL (kg) & 659,91 \\
& -Pupuk KNO3 (kg) & 432,52 \\
& -Pupuk Ammophos & 945,28 \\
& (kg) \\
\hline
\end{tabular}




\begin{tabular}{|l|l|c|}
\hline 3 & Pestisida & 13,38 \\
& -Fungisida Antracol & 1,13 \\
& (kg) & 4,63 \\
& -Fungisida Folicur & 7,18 \\
& (kg) & \\
& -Insektisida Abacel (1) & \\
& -Insektisida Dursban & \\
& $(\mathrm{l})$ \\
\hline 4 & Tenaga Kerja (HKP) & \\
& -Tenaga Kerja Dalam & $1.200,07$ \\
& Keluarga & 191,43 \\
& -Tenaga Kerja Luar & \\
& Keluarga & \\
\hline
\end{tabular}

Sumber: Data primer diolah

Dari Tabel 2 dapat diketahui bahwa pemupukan stroberi menggunakan berbagai macam pupuk, penggunaan pupuk yang paling banyak adalah pupuk kandang $(11.556,60 \mathrm{~kg} / \mathrm{ha})$ sebagai penyedia unsur hara dalam tanah. Pestisida yang digunakan petani terdiri dari fungisida dan insektisida yang membantu melindungi tanaman stroberi dari serangan hama dan penyakit. Penggunaan tenaga kerja pada usahatani stroberi di daerah penelitian didominasi oleh tenaga kerja dalam keluarga.

Efisiensi penggunaan masing-masing faktor produksi (input) terhadap produksi (output) dapat diketahui dengan membandingkan besarnya nilai produk marginal $\left(\mathrm{NPM}_{\mathrm{Xi}}\right)$ dengan harga masing-masing faktor produksi $\left(\mathrm{P}_{\mathrm{Xi}}\right)$.

Tabel 3. Pengujian Efisiensi Penggunaan

Faktor-Faktor Produksi Melalui Pendekatan Fungsi Produksi

\begin{tabular}{|l|l|l|l|}
\hline No & Variabel & $\mathrm{Ki}$ & t-hitung \\
\hline & Pupuk & & \\
& Kandang & & \\
1 & Pupuk Daun & 4,99 & 0,42 \\
2 & Pupuk & 43,15 & 1,81 \\
3 & Ammophos & 15,43 & 2,13 \\
4 & Insektisida & 64,70 & 2,51 \\
5 & Tenaga Kerja & 1,03 & 0,06 \\
\hline
\end{tabular}

Sumber: Data primer diolah

Dari Tabel 3 dapat dilihat nilai Ki masingmasing faktor produksi lebih besar dari $1(\mathrm{Ki}>1)$. Hal ini menunjukkan bahwa penggunaan masingmasing faktor produksi pada saat penelitian dilakukan relatif belum efisien. Penggunaan faktor produksi belum sesuai dengan dosis yang dianjurkan. Dengan demikian usaha untuk meningkatkan keuntungan petani di daerah penelitian masih memungkinkan yaitu dengan penambahan masing-masing faktor produksi sampai tercapai rasio $\mathrm{NPM}_{\mathrm{x}}$ dan $\mathrm{P}_{\mathrm{x}}$ sama dengan satu. Dosis anjuran untuk masing-masing faktor produksi adalah pupuk kandang: 20-30 ton/ha, pupuk daun: 22 1/ha, pupuk ammophos: 3,67 ton/ha, insektisida: $16,5 \mathrm{l} / \mathrm{ha}$, dan penggunaan tenaga kerja: $1.408 \mathrm{HKP} / \mathrm{ha}$.
C. Pendapatan Bersih Usahatani Stroberi di Daerah Penelitian

1. Biaya Total Produksi Usahatani Stroberi

Biaya total produksi dalam penelitian ini adalah seluruh biaya yang dikeluarkan petani untuk usahatani stroberi selama satu musim tanam mulai dari biaya sarana produksi, biaya tenaga kerja, biaya pajak, sewa lahan, biaya penyusutan alat , dan biaya penggunaan mulsa yang keseluruhannya dhitung dalam rupiah.

Tabel 4. Biaya Produksi rata-rata Usahatani Stroberi pada Satu Musim Tanam

\begin{tabular}{|c|c|c|}
\hline No. & Uraian & Per Hektar (Rp) \\
\hline 1 & $\begin{array}{l}\text { Biaya Variabel: } \\
\text { - Bibit } \\
\text { - Pupuk } \\
\text { - Pestisida } \\
\text { - Tenaga Kerja } \\
\text { - Biaya Mulsa }\end{array}$ & $\begin{array}{l}62.500 .000,00 \\
39.175 .235,85 \\
3.839 .622,65 \\
125.712 .264,00 \\
7.500 .000,00\end{array}$ \\
\hline 2 & $\begin{array}{l}\text { Biaya Tetap: } \\
-\quad \text { Biaya } \\
\text { PBB/Ipeda } \\
\text { - Biaya sewa lahan } \\
\text { - } \quad \text { Biaya } \\
\quad \text { penyusutan }\end{array}$ & $\begin{array}{l}143.867,92 \\
8.490 .566,04 \\
1.051 .058,52\end{array}$ \\
\hline & Total & $248.412 .614,95$ \\
\hline
\end{tabular}

Sumber: Data primer diolah

Tabel 4 menunjukkan bahwa biaya total produksi usahatani stroberi sebesar 248.412.614,95/ha/mt. Biaya terbesar pada usahatani stroberi adalah biaya tenaga kerja sebesar Rp 125.712.264/ha/mt, diikuti oleh biaya bibit sebesar Rp 62.500.000/ha/mt.

\section{Produksi dan Produktivitas Usahatani} Stroberi

Berikut ini adalah produksi dan produktivitas usahatani stroberi di daerah penelitian.

Tabel 5. Produksi dan Produktivitas Usahatani Stroberi di Daerah Penelitian

\begin{tabular}{|c|l|l|}
\hline No & \multicolumn{1}{|c|}{ Uraian } & \multicolumn{1}{c|}{ Jumlah } \\
\hline & Luas lahan rata-rata & \\
& (ha) & \\
1. & Produksi rata-rata $(\mathrm{kg})$ & 0,14 \\
2. & Harga rata-rata & $2.412,94$ \\
3. & (Rp/kg) & $22.833,33$ \\
4. & Produktivitas $(\mathrm{kg} / \mathrm{ha})$ & $17.235,3$ \\
\hline
\end{tabular}

Sumber: Data primer diolah

Dari Tabel 5 dapat dilihat bahwa luas lahan rata-rata petani stroberi seluas 0,14 ha dengan produksi sebesar 2.412,94 kg, sehingga produktivitas usahatani stroberi sebesar 17.235,3 $\mathrm{kg} / \mathrm{ha}$. Produktivitas stroberi di daerah penelitian masih dibawah potensi produksi stroberi yang dapat mencapai $18.000 \mathrm{~kg} / \mathrm{ha}$ (Prasetyo, 2017). 
3. Pendapatan Bersih Usahatani Stroberi

Tabel 6. Penerimaan, Biaya Produksi, dan Pendapatan Bersih Usahatani Stroberi di Daerah Penelitian

\begin{tabular}{|l|l|l|}
\hline No & Uraian & Per Hektar \\
\hline 1 & Penerimaan & $535.076 .650,94$ \\
2 & Biaya & $248.412 .614,95$ \\
3 & Pendapatan & $286.664 .036,00$ \\
\hline \multicolumn{3}{|l}{ Sumber: Data primer diolah } \\
Pendapatan bersih petani stroberi
\end{tabular}
diperoleh dengan mengurangkan penerimaan dengan biaya total produksi. Biaya total produksi pada penelitian ini adalah Rp. 248.412.614,95/ha/mt sehingga diperoleh pendapatan bersih usahatani stroberi sebesar Rp. 286.664.036,00/ha/mt.

\section{KESIMPULAN}

1. Secara serempak penggunaan faktor produksi pupuk Kandang, pupuk daun, pupuk ammophos, insektisida, dan tenaga kerja berpengaruh nyata/signifikan terhadap produksi usahatani stroberi. Secara parsial penggunaan faktor produksi pupuk daun, pupuk ammophos, insektisida, dan tenaga kerja berpengaruh nyata terjadap produksi usahatani stroberi, sedangkan pupuk kandang tidak berpengaruh nyata/signifikan terhadap produksi usahatani stoberi.

2. Penggunaan faktor produksi pupuk kandang, pupuk daun, pupuk ammophos, insektisida, dan tenaga kerja belum efisien, penggunaan faktor produksi tersebut masih dapat ditingkatkan untuk meningkatkan produksi usahatani stroberi.

3. Pendapatan bersih petani stroberi di Dusun Tongkoh, Desa Dolat Rayat, Kecamatan Dolat Rayat, Kabupaten Karo diperoleh sebesar sebesar Rp.286.664.036,00/ha/mt.

\section{DAFTAR PUSTAKA}

Balitjestro. 2015. Budidaya Tanaman Stroberi.

Balitjestro. 2016. Teknologi Budidaya Stroberi di Lahan.

Dinas Pertanian Kabupaten Karo. 2019. Statistik Pertanian Kabupaten Karo.

Kabanjahe.

Ghozali, Imam. 2011. Aplikasi Analisis Multivariate dengan Program SPSS. UNDIP, Semarang.

Joesron, Fathorozzi. 2003. Teori Ekonomi Mikro. Salemba Empat. Jakarta

Prasetyo, 2017. Manajemen Produksi BuahBuahan Budidaya Tanaman Buah. Intimedia. Jakarta.

Rahardi et al, 2003. Agribisnis Tanaman Buah. Penebar Swadaya. Jakarta
Rukmana, R, 1998. Stroberi: Budidaya dan Pasca Panen. Kanisius. Yogyakarta.

Saragi, C.P.H. 1992. Efisiensi Produksi pada Perkebunan Kopi Dikebun Getas/Asinan/Banaran PT. Perkebunan XVIII. Thesis S2, Universitas Gajah Mada. Yogyakarta.

Soemadi. 1997. Budidaya Stroberi di Pot dan Kebun. CV. Aneka. Solo.

Soekartawi. 1990. Teori Ekonomi Produksi Dengan Pokok Bahasan Analisis Fungsi CobbDouglas. PT. Raja Grafindo Persada. Jakarta.

2002. Prinsip Dasar Ekonomi Pertanian: Teori dan Aplikasi. Edisi Revisi 2002. PT. Raja Grafindo Persada. Jakarta.

2003. Agribisnis Teori dan Aplikasi. PT. Raja Grafindo Persada. Jakarta.

Supranto, 1994. Statistik Teori dan Aplikasi Jilid I Edisi Kelima. Grafindo Persada. Erlangga . Jakarta. 